University of Wollongong

Research Online

Faculty of Engineering - Papers (Archive)

Faculty of Engineering and Information

Sciences

$1-1-2002$

\title{
The Prediction of Thermophysical Properties for Modelling Solidification of Metallic Melts
}

P N Quested

National physical laboratory, UK

Robert F Brooks

National physical laboratory, UK

Brian J. Monaghan

University of Wollongong, monaghan@uow.edu.au

Follow this and additional works at: https://ro.uow.edu.au/engpapers

Part of the Engineering Commons

https://ro.uow.edu.au/engpapers/926

\section{Recommended Citation}

Quested, P N; Brooks, Robert F; and Monaghan, Brian J.: The Prediction of Thermophysical Properties for Modelling Solidification of Metallic Melts 2002, 25-37.

https://ro.uow.edu.au/engpapers/926

Research Online is the open access institutional repository for the University of Wollongong. For further information contact the UOW Library: research-pubs@uow.edu.au 


\title{
The Prediction of Thermophysical Properties for Modelling Solidification of Metallic Melts
}

\author{
PN Quested', RF Brooks ${ }^{1}$ and B.J Monaghan? \\ ${ }^{1}$ NPL Materials Cemtre, National Physical Laboratory. Teddington, TWII OLW, UK \\ entail:peter.quested@npl.co.uk \\ 2. Dept. of Materials, University of Wollongong. Wollongang, NSW 2522. Australia
}

\begin{abstract}
This paper briefly describes the philosophy of Ken Mills to give to industry recommended values for thermophysical properties at high temperatures with an indication of the uncertainty of measurement relevant to their processes. To achieve this Ken adopted what he called his three pronged attack:

Critically assess the data in the literature and attempt to recommend values for the properties.

Construct equipment to make the relevant measurements and perform experiments to understand inconsistencies in the literature values.

Investigate models of properties 10 aid understanding of the measurements and make realistic predictions of the properties.
\end{abstract}

The paper outlines how his successors have attempted to continue in this tradition. Recent examples of work at the National Physical Laboratory are taken. These include the review of properties and the dissemination of the results to industry; the experimental facilities illustrated from the measurement of thermal diffusivity of iron: viscosity of metals: density and surface tension; and finally recent developments for modelling thermophysical properties. 


\section{Introduction.}

Ken Mills's long career at the National Physical Laboratory, stretching from 1963 until well beyond his official retirement in 1999, has left a great legacy of work that put him in the forefront of research for the physical properties of slags, oxides and metats, hut also enabled his colleagues to benefit from his philosophy and his way of working.

Having identified a need for property measurement, Ken always relers to this three-pronged attack:

\section{1) Crifically' assess the data in the lirerature and attempt to recommend ralues for the} properties.

One need only see the number of fine reviews he authored or co-authored including his massive contribution to the $2^{\text {nd }}$ edition of the "Slag Atlas" [1]; the review of the thermal conductivities of the liquid elements [2] and recently his recent compendia about alloys [3] to appreciate the value of his authorative assessment of the literature.

2) Construct experimental equipment ro make relevan measurements and perform the key' experiments to understand inconsistencies in the literature values.

Here examples are the production of reference materials [4] for the measurement of slag viscosities together with recommendations for performing the measurement. This work has allowed the slags community to compare values from many laboratories. [5] Another important contribution was his pioneering investigations using electromagnetic levitation to measure the surface tension of metais. There is no doubt that without his insight and leadership the capabilities of NPL in the measurements of thermophysical properties of metals and slags would be far the poorer.

3) Imestigate models of properties to aid our understanding of the meastrements and also make realistic predictions of properties.

Many industrialists have used the "SLAGS" [6] and "METALS" [7] models developed in the late 1980 s to give guidance about thermophysical property values when experimental measurements were impractical because of cost or experimental difficulties.

The objective of this iterative approach is to be able to contidently recommend values for thermophysical properties with an associated uncertainty, relevant to industrial processes. Ken has atways tried to familiarise himself with the industrial processes. An example is his championing of the effects of Marigoni flow, making the link between measurement of the temperature dependence of surtace tension and its application to industry such as welding [8] and the behariour of inclusions in electron beam melting. [9]

Inevitably Ken Mills is a hard act to follow but the NPL group and their collaborators have tried to adopt his approach and this paper attempts to show how he has influenced us. It is in three parts: reviews and their implications, experimental facilities and developments, and the prediction of properties of slags and metals.

\section{Review of properties.}

During his latter years at NPL, Ken produced a compendium of physical properties of industrially important alloys. [3] He trawled the literature for data, predicted properties and also encouraged his colleugues to complete measurements where the data was sparse normally because the experiments were difticult. 
Data on the most widely used titanium alloy, $\mathrm{Ti}-6 \mathrm{Al}-4 \mathrm{~V}$. which is extremely reactive, have been gathered. Using a combination of results from two types of differential scamning calorimeters and the levitated drop calorimetry, the dependence of enthalpy from $25^{\circ} \mathrm{C}$ to above $1800^{\circ} \mathrm{C}$ into the liquid was determined together with the density in the liquid by the levitation method. [10] These data were compared to predictions using a thermodynamic model for enthaipy and a rule of mixtures model for the density; the sparse experimental work from other laboratories and he synthesised a recommended data set. Subsequent independent measurements of enthalpy have confirmed this data set. [11] (Figure 1) With this approach for each element and alloy considered Mills gives tables of recommended values, which are invaluable for the modeller simulating a process.

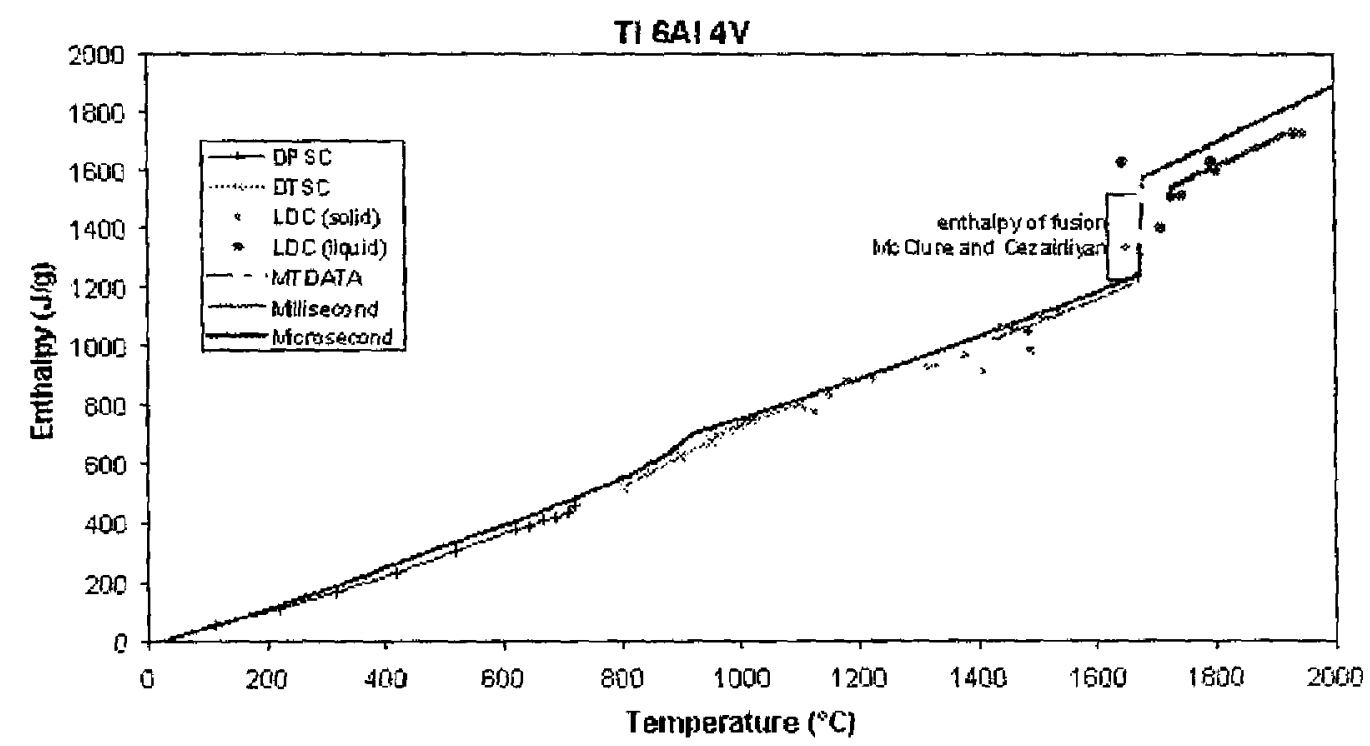

Figure 1 The enthalpy of Ti $6 \mathrm{Al} 4 \mathrm{~V}$ alloy measured with several calorimeters: a microsecond technique (Kashnitz et al.) and a thermodynamic caleulation.

The review of the thermal conductivities of molten pure metals [2] critically assesses the data in the literature for these materia!s and attempts to assign recommended values, complementing the classic review by Touloukian [12]. An important aspect of this type of review is the identification of gaps in our knowledge. For example the paucity of data for licquid iron was recognised and the problem is discussed later in this paper.

A crucial aspect of our work is to communicate the data and understanding to the scientists and technologists who use the values. Ken has always produced reviews about experimental techniques for the non specialist and about the application of the data. In recent years we have continued this approach including presentations about techniques both at conferences for modellers, [13] slags, oxides and fluxes [14]; and the foundry industry. [15]; at factories and universities; and using the internet [16] in a European collaborative programme. A forthcoming paper describes some of the challenges of interpreting and applying the data. [17]

There is an increasing drive to bring together expertise from diverse disciplines to supply a single industry with the data required to model its processes. Thus for the investment casting industry the properties of waxes used to make the moulds are drawn from the polymer field: the molten metals from the metals area and the behaviour of the investment moulds from the ceramics area. [18]. This will inevitably mean greater collaboration between scientists to complement their skills. 


\section{Experimental facilities and development.}

Table I gives an indication of the breadth of experimental facilities, which are being developed at NPL for measuring the properties of industrially important metals and slags. It covers a wide range of measurements relevant to metals and, to a lesser extent, slags. We also work closely with our colleagues at NPL and other organisations to supplement these facilities. The following are examples of the use of some of these equipments and the chalienges of measurement.

\begin{tabular}{|c|c|c|c|c|}
\hline Property & Mletliod & $\begin{array}{l}\text { Temperature } \\
\text { range, }{ }^{\circ} \mathrm{C}\end{array}$ & $\begin{array}{l}\text { Estimated } \\
\text { uncertainty } \%\end{array}$ & Relevant alloys \\
\hline $\begin{array}{l}\text { Endhalpy: } \\
\text { Specific Heat: } \\
\text { Latent deat }\end{array}$ & $\begin{array}{l}\text { Differential power } \\
\text { Scanning calotimeter }\end{array}$ & Upto 730 & $\pm 2 \%$ & $\begin{array}{l}\text { Al } \\
\text { (Mg with } \\
\text { difficulty) }\end{array}$ \\
\hline $\begin{array}{l}\text { Enthalpy; } \\
\text { Specific Heal: } \\
\text { Latent heat }\end{array}$ & $\begin{array}{l}\text { Differential Temperature } \\
\text { Scanning calorimeter }\end{array}$ & $600-1500$ & $\pm 5 \%$ & $\begin{array}{l}\mathrm{Cu} ; \mathrm{Fe} \\
\text { (lower meltisig } \\
\text { points); } \mathrm{Ni} ; \mathrm{Co}\end{array}$ \\
\hline $\begin{array}{l}\text { Enlhalpy: } \\
\text { Specific Heat: } \\
\text { Latent heat }\end{array}$ & $\begin{array}{l}\text { Single pan calorimeter } \\
\text { Levitating drop }\end{array}$ & $25-1000$ & $\pm 1 \%$ & Al \\
\hline $\begin{array}{l}\text { Enthalpy: } \\
\text { Specific Heat: } \\
\text { Latent heat }\end{array}$ & $\begin{array}{l}\text { Levitating drop } \\
\text { calorimeter }\end{array}$ & $1000-2000$ & $\pm 2 \%$ & $\mathrm{Fe} ; \mathrm{Ni} ; \mathrm{Ti}$ \\
\hline $\begin{array}{l}\text { Thermal } \\
\text { diftusivity }\end{array}$ & Laser flash & $25-2000^{\circ} \mathrm{C}$ & $\begin{array}{l} \pm 5 \% \text { solid } \\
\pm 10 \% \text { liquid }\end{array}$ & $\begin{array}{l}\mathrm{Al} ; \mathrm{Mg} ; \mathrm{Cl} ; \mathrm{Fe} ; \\
\mathrm{Ni} ; \mathrm{Co} \\
\text { Limited slags } \\
\text { work }\end{array}$ \\
\hline Density & Dilatomety & $25 \cdot 1600$ & $\pm 2 \%$ & $\begin{array}{l}\mathrm{Al} ; \mathrm{Mg} ; \mathrm{Cu} ; \mathrm{Ni} \\
\mathrm{Co} \text {;i solid }\end{array}$ \\
\hline Density & Piston dilatometty & $25-1400$ & $\pm 4 \%$ & $\mathrm{Al} ; \mathrm{Ni}$ \\
\hline $\begin{array}{l}\text { Density/sul face } \\
\text { tension }\end{array}$ & $\begin{array}{l}\text { lmaging drops such as } \\
\text { sessile and levitation }\end{array}$ & $1000-2000$ & $\pm 2 \%$ & $\mathrm{Cu} ; \mathrm{Fe} ; \mathrm{Ni}: \mathrm{Co} ; \mathrm{Ti}$ \\
\hline $\begin{array}{l}\text { Density/surface } \\
\text { tension }\end{array}$ & Archimedean methods & $20-1300$ & $\pm 3 \%$ & $\begin{array}{l}\text { Al; } \mathrm{Cu} \\
\text { Slags }\end{array}$ \\
\hline $\begin{array}{l}\text { Density/surface } \\
\text { tension }\end{array}$ & $\begin{array}{l}\text { Maximum bubble } \\
\text { techniques }\end{array}$ & $20-1300$ & $\pm 4 \%$ & $\begin{array}{l}\mathrm{Al} ; \mathrm{Cu} \\
\text { Slags } \\
\end{array}$ \\
\hline Viscosity & $\begin{array}{l}\text { Oscillating cup } \\
\text { visconteter }\end{array}$ & $20-1600$ & $\pm 10 \%$ & $\mathrm{Al} ; \mathrm{Co} ; \mathrm{Ni} ; \mathrm{Fe}$ \\
\hline Viscosity & Rotatiug bob & $20-1600$ & $\pm 10 \%$ & Slags and glasses \\
\hline
\end{tabular}

Table 1: Some measurement techniques available at NPL

\subsection{Thermal diffusivity of iron. [19]}

Thermal diffusivities of liquid metais are difficult to measure because:

1) chemical reactivity causes problems of contaimnent for metals at high temperatures. Containers of sapphire are normally employed to minimise this problem.

2) if density driven convection occurs, it affects the result and care must be taken to minimise its occursence by stable sample temperatures and performing the measurement quickly.

There are very few direct measurements of either the thermal conductivity or diffisivity of liquid iron. [2] A further problem associated with the measurement of the thermal diffisivity of iron by the laser flash method is that the graphite coating used to improve the signal dissolves in the iron. Monaghan [19] developed the use of a ceramic coating (zirconia) to fulfil the same tunction as the graphite coating without the dissolution problems. 
Graphite is effectively insoluble in liquid copper so he demonstrated that above $650^{\circ} \mathrm{C}$ the measured thermal diffusivities of copper using graphite and zirconia coatings $(-25 \mu \mathrm{m}$ thick) were very similar. The proposed explanation for the lower values found below $650^{\circ} \mathrm{C}$ with the zirconia coating is that the heat conduction properties of the coating are dominated by relatively slow lattice (phonon) conductivity but above $650^{\circ} \mathrm{C}$ radiation (photon) conduction is increasingly important. (figure 2)

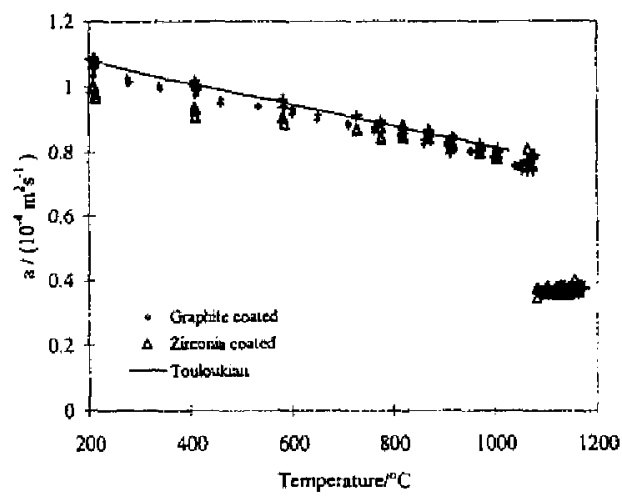

Figure 2: Comparison of thermal diffusivity of copper measured with a graphite or zirconia coating. The accepted values from Touloukian are also shown.

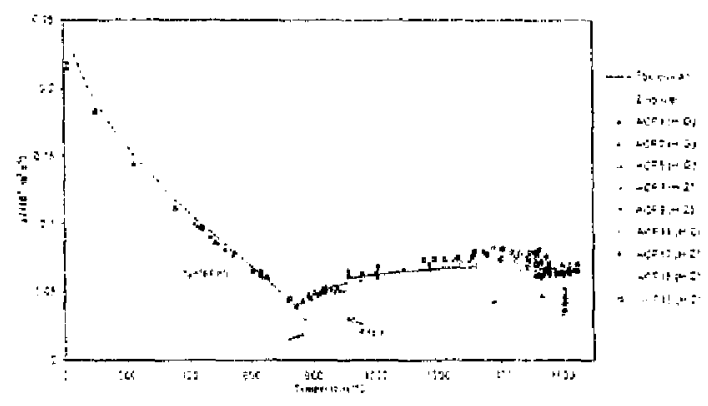

Figure 3: Thermal diffisivity measurements for pure iron.

Figure 3 shows the results for iron using this modified technique and the values are in reasonable agreement with those quoted by Touloukian [12] to the $\alpha$ to $\gamma$ transition but above about $1200^{\circ} \mathrm{C}$ the only data are by Zinovyev [20] who employed a system using an electron beam. There are disagreements between the two sets of data and the present authors tentatively support a new recommended value for the thermal diffissivity $\left(\mathrm{m}^{2} \mathrm{~s}^{-1}\right)$ as a finction of temperature $\left({ }^{\circ} \mathrm{C}\right)$ for the liquid.

$$
\alpha=6.2 \times 10^{-6}+1.79 \times 10^{-9} \times(\mathrm{T}-1538)
$$

This work would now be best served by a round robin in which a number of laboralories measure the thermal diffusivity of iron.

\subsection{Viscosity of liquid metals. $[21,22]$}

The experimental difficulties of measuring the viscosity of liquid metals are well documented in lida and Guthrie's book. [24] An oscillating cup viscometer [21] was constructed at NPL with an upper temperature capability of $1650^{\circ} \mathrm{C}$. The mechanics of the apparatus are similar to those used by other workers but it incorporates a unique detection system, which enables the waveform of the decaying sinusoidal motion to be constructed. Figure 4 shows the results of the viscosities of nickel and a superalloy demonstrating the repeatability of the measurements are higher than those using a different detection system.

The conversion of the damping oscillation to viscosity are normally analysed [24.25] using Roscoe's equation $[23,24$ ], mainly for reasons of simplicity of presentation of the working formulae of that reference. Kestin, Newell and Beckwith [28,29] described a more complete model for the determination of viscosity using the oscillating cup viscometer and this model was implemented by Brockener et al. [30]. Recently, it has been suggested that the Beckwith-Newell 
model is more accurate and comprehensive than that of Roscoe and should therefore be adopted tor future analysis of viscosity data.

Ferriss and Quested [22] present work to clarify this suggestion by comparing results for the two models calculated from typical data generated at NPL. One unexpected result of this work is that they discovered a mis-print in the original form of the Roscoe equation (2) in reference [23].

The numerator of the second term is omitted. However, in a number of subsequent publications (e.g. references $[21,24,26,27]$ ) the complete term appears as $(-\Delta / 2)$. Expansion by the binomial theorem and subsequent simplitication yields the term $(-3 \Delta / 2)$. This has been confirmed using the symbolic algebraic system REDUCE.

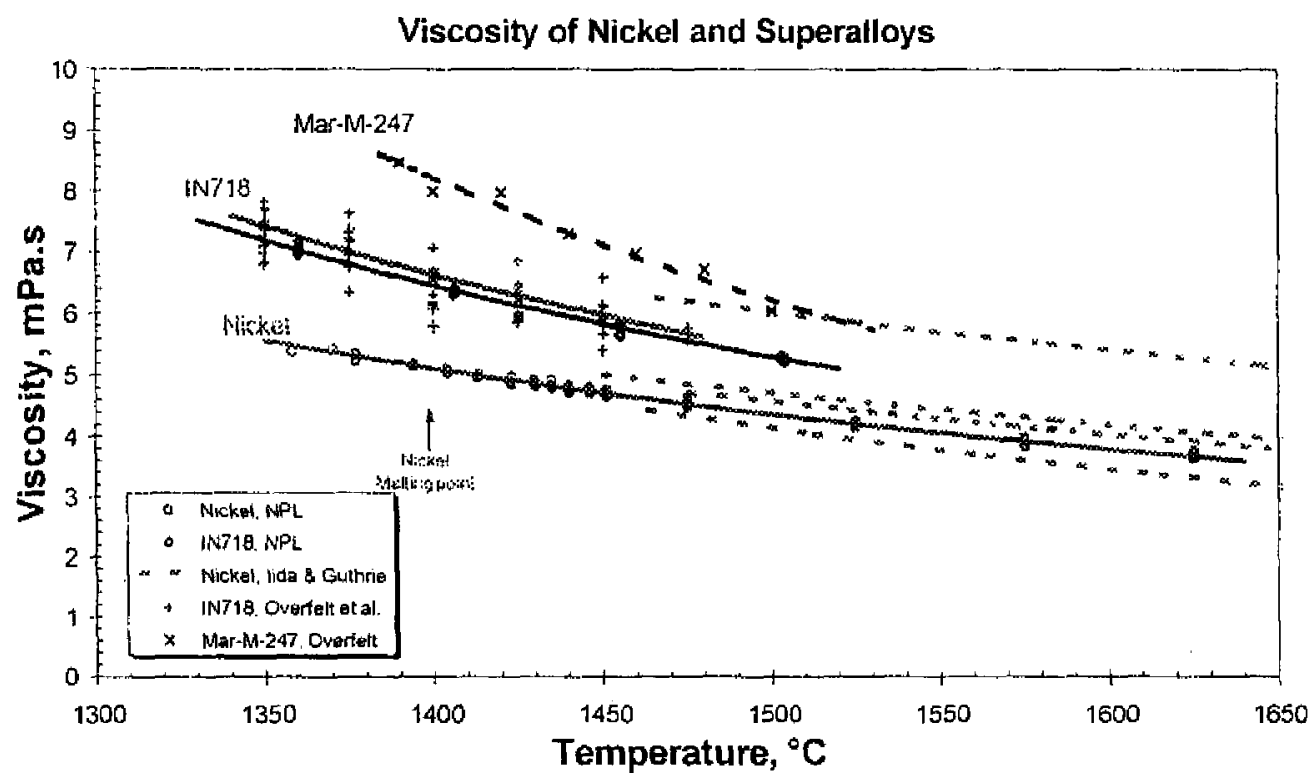

Figure 4: The viscosities of nickel and nickel-base superalloys measured by various authors.

Roscoe [23] describes the derivation of the necessary formulae for determining viscosity from oscillatory spherical and cylindrical viscometers.

$$
\begin{gathered}
\left.M=\frac{R^{3} H}{2}(\pi n \rho T) /\left(1+\frac{1}{4} \frac{R}{H}\right) a_{0}-\left(\frac{3}{2}+\frac{4}{\pi} \frac{R}{H}\right) \frac{1}{p}+\left(\frac{3}{8}+\frac{9}{4} \frac{R}{H}\right) \frac{a_{2}}{2 p^{2}}-\left(\frac{63}{128}-\frac{45}{64} \frac{R}{H}\right) \frac{a_{+}}{4 p^{4}} .\right] \\
a_{0}=1-\frac{3}{2} \Delta-\frac{3}{8} \Delta^{2}-\frac{1}{16} \Delta^{3} \ldots \\
a_{2}=1+\frac{\Delta}{2}+\frac{1}{8} \Delta^{2}-\frac{1}{16} \Delta^{3} \ldots \\
a_{4}=a_{2} /\left(1+\Delta^{2}\right)^{1 / 2}=1+\frac{\Delta}{2}-\frac{3}{8} \Delta^{2}-\frac{5}{16} \Delta^{3} \ldots \\
p=(\rho \pi / \mu T)^{1 / 2} R .
\end{gathered}
$$

and

In (1). $R$ is the cylinder radius, $H$ the height of the liquid within it, I is the moment of inertia of the suspension. $2 \pi \Delta$ the logarithmic decrement between consecutive swings, $\rho$ is the lluid density - ו the viscosity and $\mathrm{T}$ is the period of oscillation. 
The effect of the error in the expansion for $a_{0}$ is as follows. With the error re-introduced the steel value becomes $5.762 \mathrm{mPa}$ (a discrepancy of $4.7 \%$ ) and that for aluminium becomes 0.937 $\mathrm{mPa}$ (a discrepancy of $1.3 \%$ ). It is perhaps debatable whether these differences would be considered serious, atthough they may be significant in some circumstances.

Substitution of the steel data into the corrected Roscoe equation and subsequent numerical solution for the viscosity gives $6.047 \mathrm{mPa}$. . The corresponding value calculated using the Beckwith-Newell analysis yields $6.048 \mathrm{mPa}$.s. For the aluminium data, the viscosity results for the Roscoe and Beckwith-Newell analyses are $0.949 \mathrm{mPa}$. $\mathrm{s}$ and $0.954 \mathrm{mPa} . \mathrm{s}$ respectively. The difference between the results for aluminium is about $0.5 \%$ and that for steel very much less.

\subsection{Oxide skin effects on the oscillations of electro magnetically levitated metal drops.}

Many workers have measured the surface tension of liquid metals $(\gamma)$ from the oscillation frequencies of levitated drops using the Rayletgh relation. [31]

$$
\gamma=(3 / 8) \pi \mathrm{m}(1)^{2}
$$

where $m$ is the mass of the drop; $w$ is the frequency of oscillation. The advantage of using levitation and thus removing the container as a significant cause of contamination was recognised by many, but measuring the oscillations was difficult and time consuming. By introducing fast Fourier transforms to analyse the oscillations, not only did Keene [32] find a rapid measurement method, they also found that during terrestrial measurements, instead of a single oscillation frequency predicted by Rayleigh, a spectrum containing three or five dominant oscillations frequencies are found. This is due to deformation the drop shape by gravity and the supporting magnetic field. Cummings and Blackburn [33] aligned the frequencies to three modes of oscillation. and derived a correction factor to obtain the Rayleigh frequency. Egry et al.[34], through comparative measurements made terrestrially, and in microgravity, (where due to minimal gravity the drop shape is not distorted), and a single oscillation frequency can be measured, demonstrated the validity of these corrections. Keene and Mills amassed data on various steels, and derived simple rules to relate sulphur and calcium content to their surface tensions, and from that to a measure of their comparative weldability [8]. picking up on the theories of Heiple and Roper [35] of Marangoni driven fluid flow in the weld pool. A European project to investigate materials to provide a reference for high temperature liquid metal surface tensions [36] compared three different levitation apparatus with sessile drop, and found a $2.4 \%$ uncertainty in the data for copper from the melting point to $1600{ }^{\circ} \mathrm{C}$. and a $3.6 \%$ uncertainty in the results for nickel from $1150^{\circ} \mathrm{C}$ (undercooled) to $1700^{\circ} \mathrm{C}$. proving the reliability of the method.

In further work Brooks and Day studied nickel alloys and found, where oxide formed on the surface of the drops as thin layers or islands, damped, or more complex oscillation spectra could be observed, exhibiting up to nine oscillation frequencies [37]. By instigating an image analysis system based on that of Egry, they have been able to derive surface tension data from these spectra, which agrees with data from the more normal, five peak spectra. However, further work is required to determine how the oxides interact with the oscillation modes to give such spectra. 
Figure 5: Levitated drop trequency spectra: (A) drop covered with oxide skin at $1600^{\circ} \mathrm{C}$; (B) drop partially covered with oxide film at $1615^{\circ} \mathrm{C} ;$ (C) normal oscillations at $1690^{\circ} \mathrm{C}$. Subscripts $D$ and $I$ denole use of diode or Image analy'sis sy'stems respectively'
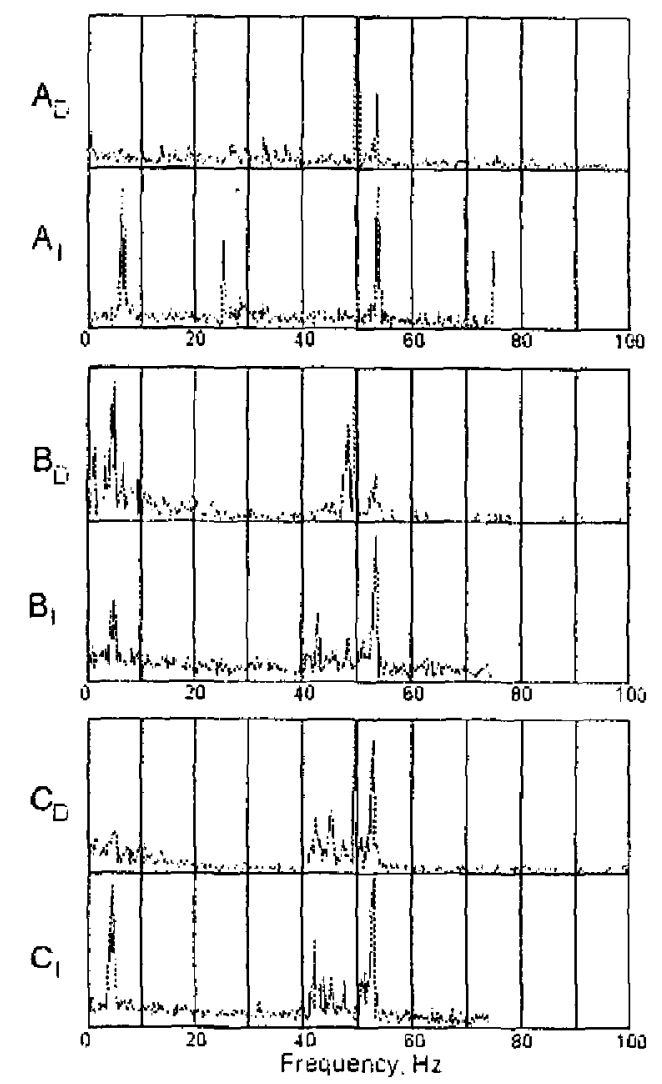

\section{Oscillations of a Levitated Drop Captured at $150 \mathrm{~Hz}$}

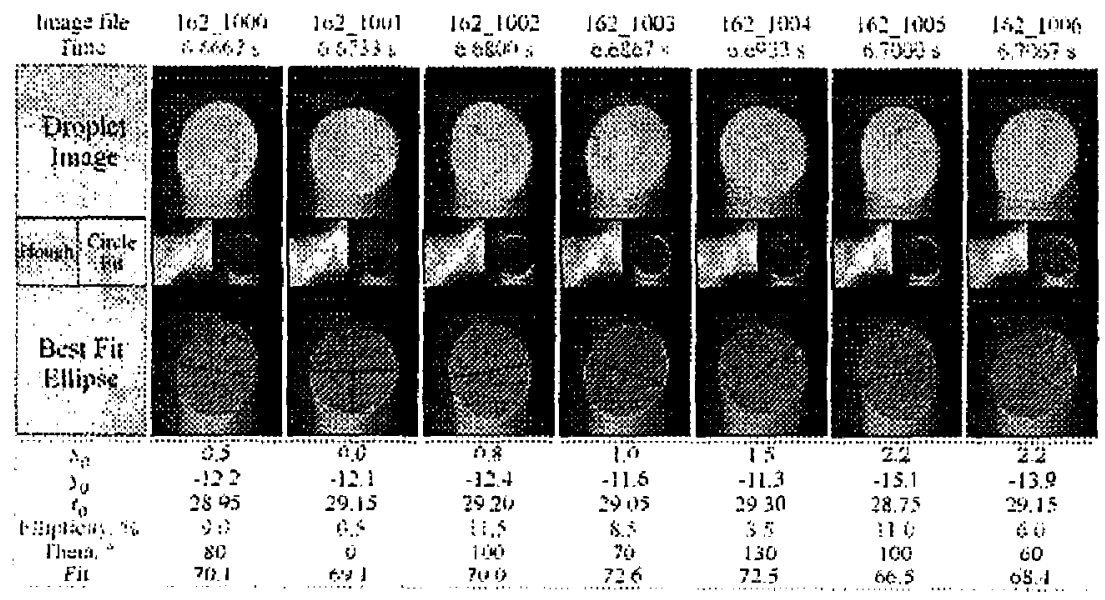

Figure 6: Example images of a levitated drop captured using a high speed camera. The images have been analysed automatically: and fitted to a generalised ellipse 


\subsection{Other surface tension and density measurements}

Surface tension and density may be determined by a number of methods, each with their own advantages and limitations and often only applicable to certain materials. In recognising the importance of these properties, the paucity of data available for high temperature systems, and the need to compare data obtained by different methods. NPL has supported the development of a range of measurement methods. These methods include: levitation, as mentioned above; maximum bubble pressure; sessile drop; high temperature dilatometry and hydrostatic probe. Morrell has developed a piston dilatometer capable of measuring the thermal expansion of a sample through the melting range and into the liquid. This can provide an important indication of the density of the mush, and of the point where the structure will collapse, as well as high temperature solid and liquid expansion coefficients. As well as making measurements of alloys and slags at high temperatures, emphasis has been placed on being able to operate in atmospheres representative of those found in industry, so that tests can mimic industrial processes, giving a greater insight into how these processes work. Measurements on a copper slag were made by maximum bubble pressure to obtain surface tension and density values [38]. At high temperatures both properties could be determined, but at temperatures below $1370^{\circ} \mathrm{C}$ the measurements of bubble pressure obtained at different depths in the liquid became inconsistent. The solidified sample showed some sign of stratification but an explanation could only be found through thermodynamic modelling of phase equilibria using MTDATA, when using the ability to vary the oxygen potential.: at certain $\mathrm{pO}_{2}$ solid phases formed at lower temperatures. This knowledge explained the stratification and the increasing pressures with depth, and could be uised by the end users to ensure control of their process and reduce blockages.

\section{Models for the prediction of properties.}

Industrial processes, such as casting and primary metal production. are frequently simulated using physical models, which recuire properties of alioys and slags as a function of temperature in the liquid, liquid/solid and solid regions, including liquidus and solidus temperatures, fraction solid. enthalpy, heat capacity, density and thermal conductivity. Unfortunately thermophysical properties of alloys can be difficult and expensive to measure and it would help the modeller to make sensible predictions of these properties based only upon the chemical composition of the alloy. In the past most models have fallen into one of two types : the thermodynamic models, such as MTDATA developed at NPL, powerfil tools which requires a trained operator, and single property models, such as Urbain's viscosity models. Mills took the first step to amalgamate various models into SLAGS and METALS, and recently NPL has taken the concept further to fuse thermodynamic calculations to mathematical and empirical models in a simple-10use package [39].

In this NPL model, the prediction of liquidus, solidus, enthalpy, volume fraction and density of metals and oxides are based upon thermodynamic models [40] and critically assessed data allowing the properties to be calculated both as a function of temperature and composition. The database is unusual since volume, and hence density, can be calculated directly through the differential of the Gibbs energy with pressure. The thermal conductivity is estimated using empirical relationships based upon work by Powell [41] and Mills [3,7]. A prediction of the fraction solid and phase fractions is made and some allowance for non-equilibrium solidification using the Gulliver - Scheil approximation. The program interface is designed to be easily used by an engineer with no knowledge of thermodynamics (figures 7 and 9). 

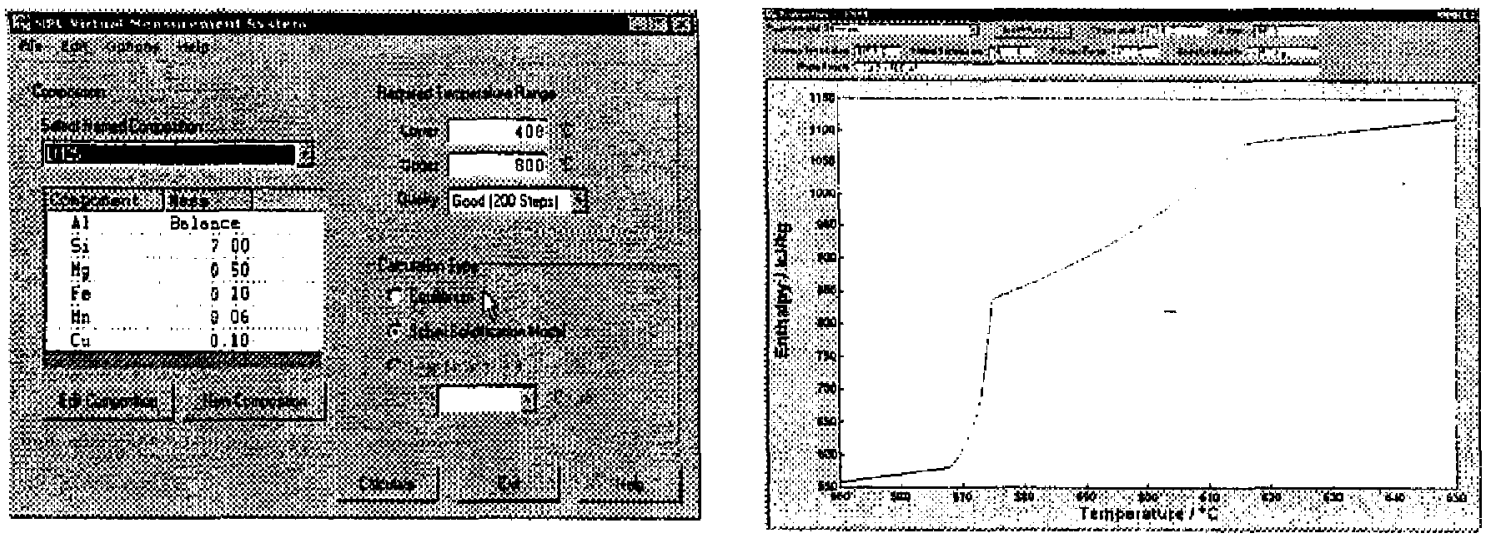

Figure 7 Program interface (left) and typical results screen (right) for the virtual measurement system
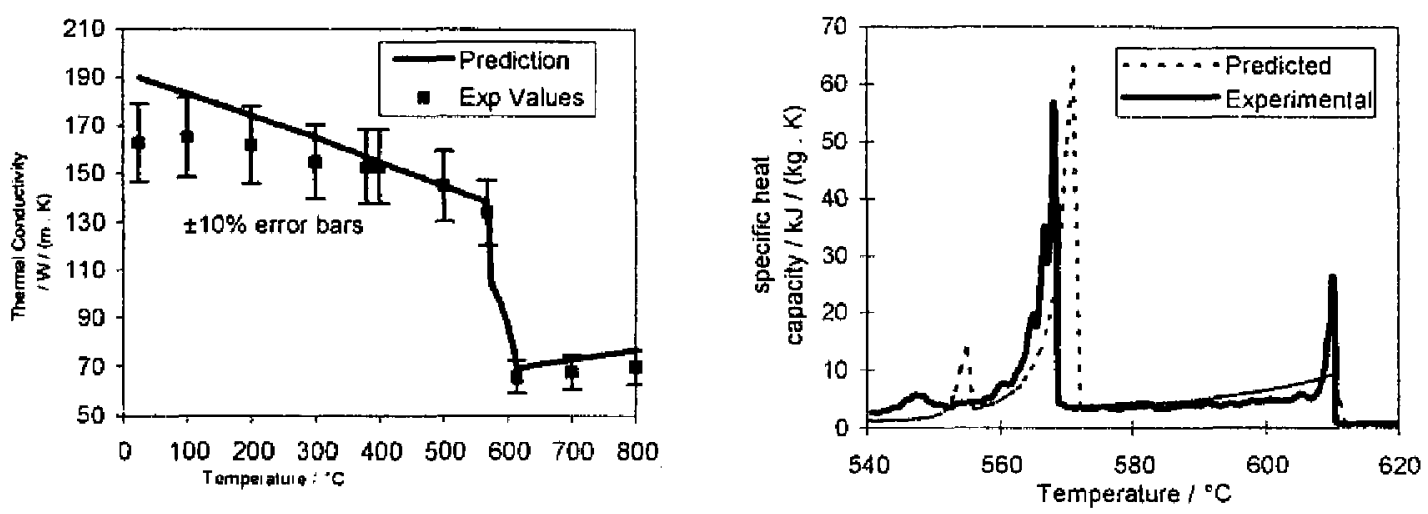

Figure 8 Predicted and derived thermal conductivity data (from measured thermal diffusivity) and measured specific heat capacity (right) for LM25.

One version of the program is construcled for aluminium alloys containing up to seven components (Al. Fe. Si. Mn, $\mathrm{Cu} . \mathrm{Mg}, \mathrm{Zn}$ ). applicable to a wide range of industrial alloys used in cast and wrought products. If the thermodynamic data are available the number of components can be extended beyond seven, although there is a time penalty for the calculations with increasing complexity.

To determine liquidus and solidus temperatures a heat flux calorimeter ("Smith" calorimeter) was constructed which gives better results than a conventional DSC [42]. Also the density was measured across the mush using a piston dilatometer [43] The measured results for the well characterised aluminium alloy, A356 or LM25, are compared with the predictions, figures 8 and 9. The agreement is satisfactory except for the thermal conductivity of the solid because the value of this property is critically dependent on the microstructure.

The concept of this program can be applied to other classes of alloys provided that the thermodynamic data including volume data are available and a preliminary program has been written to predict some properties of slags as a function of temperature and composition using an 
oxide data base [44,45] and previously published models by (Jrbain [46] or Seetharaman [47] for viscosity.

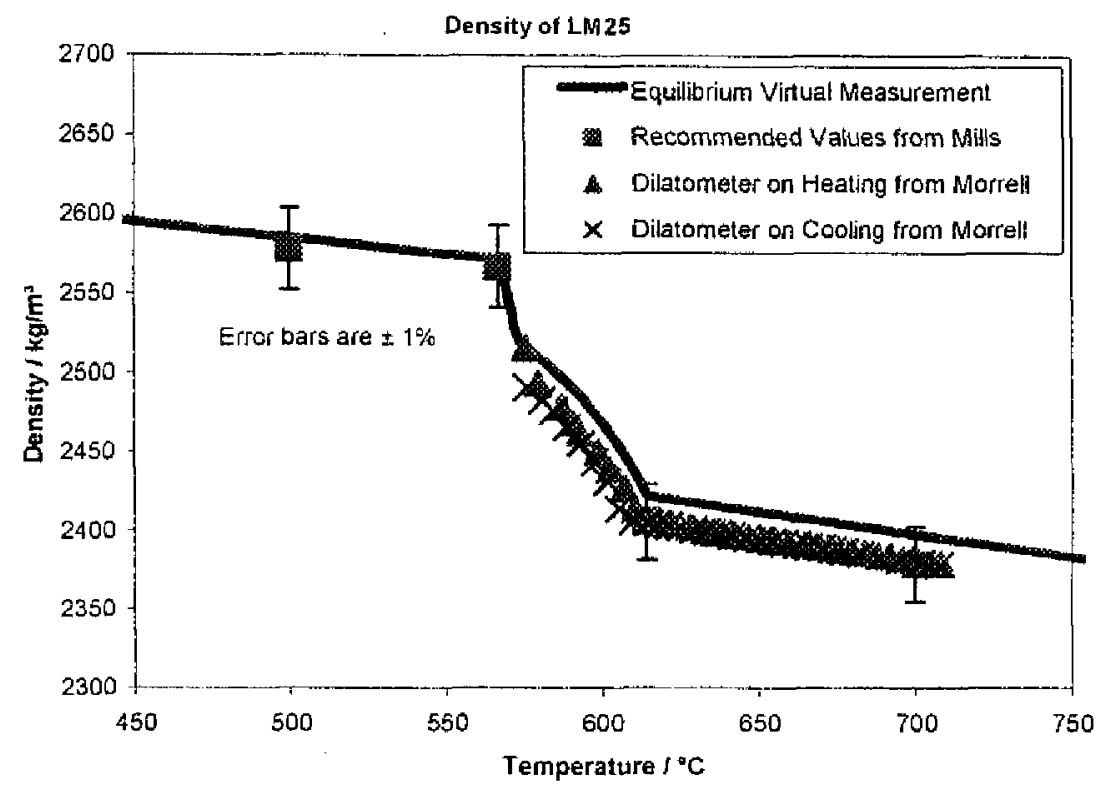

Figure 9 Comparison of the measured and predicted density for a typical composition of L.M25

\section{Conclusions.}

Ken Mills worked at NPL for many years, with many co-workers and collaborators. The contributions to the understanding of the measurement of thermophysical properties at high temperatures and the peer reviewed publications by which the knowledge and expertise have been disseminated are legion. The present paper gives a very brief insight into his work and the few examples chosen show the legacy of Ken's work, influences and contributes to the present research at the National Physical Laboratory.

\section{Acknowledgements.}

Much of this work was undertaken as part of the Materials Measurement Programme of the Department of 'Trade and Industry, UK.

The authors wish to thank their colleagues at NPL who contributed to this work and the encouragement they have received over the years from the members of the Industrial Advisory Group.

\section{References}

[1] "Slag Atlas", 2" Edition, Edited by VDEh Published by Verlag Stahleisen GmbH 1995 , ISBN 3-51 4-00457-9

[2] Mills. K C, Monaghan. B J and Keene, B J. Int. Mat. Rev. 41, 1996. 209 
[3] Mills, K C. "Recommended Values of Thermophysical Properties for Selected Commercial Alloys" Woodhead Publishing Ltd: Cambridge. 2002.

ISBN 1855735695

[4] Broadbent, C P. Franken, M, Gould, D and Mills, K C 4 Tli International Conference on Molten Slags and Fluxes. 8-1 $1^{\text {ti }}$ June 1992, Sendai. Japan; published by the Iron and Steel Institute of Japan; 429

[5] Mills, K.C:Chapman, L,Fox, A.B, Stidhar, S Scand. J Metallurgy,30, 2001, 396

[6] Mills, K C "Manual for the Interactive Software for Calculating the Physico-Chemical Properties of Slags Version 1.07." Available from NPL, 1990.

[7] Mills, K C; Day, A P and Quested, P N "Estimating the Thermophysical Properties of Commercial Alloys" Proceedings of the Nottingham University-Osaka University Joint Symposium University of Nottingham. September 1995.

Also see reference 3 page 233.

[8] Lancaster, J F and Mills. KC "Recommendations for the avoidance of variable penetration in GTA welding" Intl. Inst. Welding Recommendations No. 212-796-91 (1991)

[9] Lee, P D, Quested, P N and McLean. M Phif.Trans. R.Soc.Lond. A356, 1998, 1027

[10] Brooks R F, Robinson S A J, Chapman L A and Richardson M J. "The Enthalpy of a Solid and Liquid Titanium Aluminium Vanadium Alloy" to be presented at the ECTP 3-5 $5^{\text {th }}$ September 2002.

[1 1] Kasclunitz E. Reiter P. McClure J L. International Journal of Thermophysics 23, 2002. 267

[12] Touloukian Y S, Powvell, R W, Ho, C Y and Klemens, PG "Thermophysical properties of matter: Vol.1. Thermal conductivities of metallic elements and alloys." 1970, New York. IFI/Plenum

[13] Quested, P N and Brooks, R F. "Thermophysical Properties for Simulation Modelling." Proceedings of "Modelling of Casting, Welding and Advanced Solidification Processes IX" Proceedings of the 9 th International Conference edited Sahm. Hansen and Conley' held in Aachen August 20-25 $5^{\text {ih }}$ published by Shaker Verlag GmbH Aachen ISBN 3 8265-7230-0

[14] Quested. PN and Monaghan. B.1. High Temperature Materials and Processes. 20. 2001. 219

[15] Quested. PN "High Temperature Measurement of Phy'sical Properties for Casting Simulation." Proceedings of the $64^{\text {th }}$ World Foundry Congress, $11-14^{\text {th }}$ September. 2000 , paper GB44

[16] Ludwig, A, Quested, P and Neuer, G Advanced Engineering Materials, 3. 2001. 11. Also see the web site at www.gi.rwth-aachende/mebsp-b/

[17] Mills. K C. Monaghan, B J, Brooks, R F and Quested, PN "Some Cautionary notes on the measurement and use of thermophysical property data" accepled by High Temperatures-High Pressures, 34,2002, 253

[18] Brooks, R F, Chakravorty, S, Morrel!, R, Ford. D A and Quested, PN "Thermophysical Property Data for Investment Casting-What do You Need and Where do you Get it?" to presented at the $25^{\text {th }}$ European Investment Casting Federation (EICF). 16-19 June 2002. Berlin, Germany.

[19] Monaghan, B J and Quested, P N ISIJ, 4!, 2001, 1524

[20] Manzhuyev, V M. Taluts, S G, Sandakova, Vlasov, B V and Zinovyev, V E Phys. Met. Metallogr. 70, 1990, 195.

[21] Brooks, R F, Day, A P, Andon, R J I. Chapman. I. A. Mills. K C and Quested. PN. High Temperature-High Pressure 2001, 33. 73

[22] Ferriss D H and Quested PN "The Choice of Equations for the Measurement of Viscosity by the Oscillating Cylinder Method" to be presented at the EC'TP 3-5 th September 2002.

[23] Roscoe, R. 1958. Proc. Phys. Soc., 72.576 
[24] lida, T and Guthrie. R. The Physical Properties of Liquid Metals, Clarendon Press, 1988.

[25] Wittenberg, L J and Orte, D. Viscosity of Liquid Metals in Technicues of Metals Research, Vol IV, Part 2, Interscience, New York, 1970.

[26] Thresh, H R. Trans. Metallurgical Soc. AIME, Vol 233, 1965, 79

[27] Overfelt, R A, Matlock. C A and Wells, M E. Met Trans B. Vol 27B, 1996. 698.

[28] Kestin, J and Newell, G F. Theory of Oscillation Type Viscometers: The Oscillating Cup. Pt I ZAMP Vol VIII, 1957,433.

[29] Beckwith, D A and Newell, G F. Theory of Oscillation Type Viscometers: The Oscillating Cup. Part II. ZAMP Vol VIII, 1957, 450.

[30] Brockner, W, Torklep, K and Oye, H A. Ber. Bursenges Phys. Chem., 83, 1979. 1

[31] Lord Rayleigh, Pro. Roy. Soc. 29, 1879.71

[32] Keene B J Use of the Fourier analyser NPL report DMA(A)56 1982

[33] Cummings D \& Blackburn D J J. Fluid. Mech. 224 (1991), 395

[34] Sauerland S, Brooks R F, Egry I and Mills KC Containerless Processing: Techniques and Applications ed. W Holmeister, The Minerals, Metals and Materials Society 1993

[35] Heiple C R \& Roper J R Weld J. 61(4) 97-102 1982

[36] Brooks R F, Mills K C, Egry I, Seetharaman S, Grant D High Temperatures High Pressures. 33, 2001,631

[37] Brooks R F \& Day A P Int J Thermophysics. 20, 1999. 1041

[38] Monaghan B.J and Brooks R.: Thermo-Physical Properties of Slags for Process Control, Ironmaking and Steelmaking, Vol. 29, 2002.

[39] Robinson, JAJ; Dinsdale, AT; Chapman, LA; Monaghan, BI; Morrell, Rand Quested PN "The Prediction of Thermophysical Properties for Modelling Solidification of Metallic Melts" to be presented at the ECTP, London, $3-5^{\text {th }}$ September 2002.

[40] Davies RH, Dinsdale AT, Gisby JA, Robinson JA.I, Martin SM. Calphad, 2002, accepted for publication

[41] Powell, RW, Int. J. Heat Mass Transfer, 8, 1965, 1033

[42] Dong, HB, and Hunt JD, Journal of Thermal Analysis and Calorimetry, 64, 2001, 3\$1

[43] Morrell. R and Quested, P.N, NPL Report CMMT(A)106, 1998

[44] Barry, Tl; Dinsdale, AT and Gisby, JA, JOM, 45, 1993, 32

[45] Gisby, JA; Dinsdale, AT; Barton-Jones, I; Gibbon, A; Taskinen. PA; and Taylor, JR: "Predicting Phase Equilibria in Oxide and Sulphide Systems", in "Sullide Smelting 2002" eds RL Stephens, HY Sohn, (TMS Annual Meeting, Seattle 2002)

[46] Urbain G, Cambier F, Deletter M, Anseau M R: Brit Ceram Soc 80 (1981)139

[47] Ji F-Z, Du Sichen. Seetharaman S, Met Trans B 28B (1997) 827 